\title{
A Research into Related Legal Control of Cross-border Transfers of Hazardous Waste
}

\author{
Qiang Cao \\ University of Science and Technology Liaoning. China
}

\begin{abstract}
With the rise of our country's economic status, environmental issues are also increasingly attracting our attention. On the one hand, when our country exports a large number of products to other countries around the world, waste products are stranded in China. In the meantime "world factory" is "world dump", too; on the other hand, ,some developed countries has been transferring hazardous waste to China, one of the main destinations. There is a huge gap between developed countries and developing countries in economy and technology, whose demands of interests are different. Therefore, both International treaties and domestic laws are faced. with legislative defects and poor execution. Based on the present situation of related Chinese legal control of cross-border transfers of hazardous waste, some problems are analyzed and the corresponding solution is put forward.
\end{abstract}

Keywords-cross-border transfers; legal control; hazardous waste

\section{THE PRESENT SITUATION AND TREND OF} CROSS-BORDER OF CROSS-BORDER TRANSFERS OF HAZARDOUS WASTE

\section{A. The situation of cross-border transfers of hazardous waste}

In the late 1980s, cross-border transfers of hazardous waste are more and more serious. Developed countries, considering different standards of environmental regulations, transfer a large number of hazardous waste to developing countries, which thus become a "safe harbour of pollution". In the first International Forum on Sustainable Consumption and Sustainable Production in 2003, Greenpeace International said that in the1980s the main destination of trading in hazardous waste is African countries. In the mid 1990s, it is expanded into Eastern European countries. In the late 1990s the trading range began to be extended into Asian countries.

In recent ten years, the trading volumes of hazardous waste have rapidly increased. In 2007 the global trading volumes of hazardous waste increased to1.91 billion tons, which have increased by $67 \%$ in comparison with 1.14 billion tons in 2002."Although a large number of hazardous waste which is transferred to other countries is used to be reused and recycled, more hazardous waste is passed on to the "safe harbour of pollution". Based on the data of UN Comtrade, the following three tables are sorted, which respectively list the first ten countries exporting waste around the world, countries importing waste, and the first ten developing countries importing waste and visually display the amount and trend of cross-border transfers of hazardous waste.44The table also synthesizes a statistical datum which covers 92 developed countries and developing countries ,in which the relevant national environmental legislation is indexed. The results show that the rigor of regulations of environmental protection is a decisive factor of hazardous waste trade.

B. Reasons for cross-border transfers of hazardous waste

First, the growth in the total amount of hazardous waste is a prerequisite for seeking cross-border transfer. The hazardous waste production and the national industrialization is proportional to a great extent. The more developed the economy is, the more hazardous waste. The environmental standards of developed countries continue to improve. On the one hand, the scope of hazardous waste is wider and wider, which leads directly to the growth in the total amount of hazardous waste; on the other hand, demands for harmless treatment of hazardous waste gradually increase, and the treatment costs increase sharply. Therefore, developed countries and enterprises are under heavy pressure .As a result, they try to find ways to alleviate environmental and economic pressure at the expense of destroying the environment in developing countries.

Second, The profit pattern of the market economy dominates cross-border transfers of hazardous waste through international trade.Although the cross-border transfer of hazardous waste need more transportation costs, the low cost of disposing of shazardous waste in developing countries is still a major attraction for the enterprises of developed countries . For example, in America the cost of disposing of the risk containing PCBs is up to3000 dollars a ton, while the cost of exporting to Africa to be disposed of is only 2.5 dollars a ton.

Third, circumvent the regulation in the name of legality. Typically, the importing countries would agree that the hazardous waste which can be recycled, reused, and has economic value is imported, and the main subject of legitimate international waste trade is such a waste.

Actually, though some countries are taking measures in the right direction, a lot of developing countries and countries in the period of economic transformation do not have the conditions above. The collection and disposal of hazardous waste has exceeded the traditional ability of local governments. Because the international community strengthen the control of cross-border transfers of hazardous waste , many exporters dump garbage in reality 
in the name of "recycling, recycling" ,there is a growing trend towards the false recycling, true cross-border disposal.

\section{LEGAL CONTROL OF CROSS-BORDER TRANSFERS OF HAZARDOUS WASTE}

The main contents of legal control of cross-border transfers of hazardous waste include: dispose of irregularities judicially, enforcing the law solves the lack execution, legislation makes up for the blank or the lack and strengthens the public consciousness by educating environmental protection. Because cross-border transfers of hazardous waste and domestic laws are closely related, the waste import and export management system in domestic laws becomes the first legal barrier; the implementation of domestic environmental regulations and standards also determines how much hazardous waste is harmlessly treated. Meanwhile, the cross-border transfers of hazardous waste also affect importers, exporters, transit countries, which becomes the world's environmental issue. Therefore, the principles of international environmental laws, which come into being in the environmental communication, become an important international law basis of solving cross-border transfer of hazardous waste. International environmental law is a branch of international law, which not only has some in common with international law, but also has its particularity .For example, respecting implementation, the "non mandatory internal implementation program" and the "Framework Convention" mode respecting formulation, in other words, which only provide procedural requirements and abstract objective regulations, instead of specific obligation sand behaviors. It is because the national compulsory in international environmental law is relatively abstract that all countries need to cooperate more to perform it, namely fulfill its international obligations by using domestic legislation or other means to transform and perform international obligations.

\section{CHINESE LEGAL CONTROL OF CROSS-BORDER TRANSFER OF HAZARDOUS WASTE}

\section{A. The conditions of implementing the convention in China}

China signed "Basel Convention on March 22, 1990".On September 41991 the twenty-first meeting of the Seventh National People's Congress Standing Committee approved it. The state environmental protection administration is the implementation and focal points of the Basel convention. China, one of the earliest signatories to the "Basel Convention", participates actively in all the activities that the Convention has developed, and make a lot of work in the implementation of the Convention. China not only performs its obligation sin strict accordance with the provisions of the Convention, but also makes domestic laws to curb the illegal trade of hazardous waste. At present, China's regulations on cross-border transfer of hazardous waste, with "solid waste law" at the core, shall blame the perpetrators for illegal transfer of hazardous waste according to the administrative law, criminal law, civil law, etc. The victims can get compensation or administrative compensation judicially.

First, make regulations and standards to control the import of hazardous waste. From the accession of the Convention on, China formulated "solid waste law" and other relevant laws. Chinese authorities to implement the Convention--the State Environmental Protection Administration has also issued a lot of policies and regulations, and made the corresponding technical specifications.

Second, make national hazardous waste list. On January 4th 1996 the State Environmental Protection Administration, the State Economic and Trade Commission, the Ministry of foreign trade and the Ministry of Public Security jointly issued the "list of national hazardous waste", including categories of wastes, waste to come and send. After wards, "list of waste restricting import which can be used as raw materials ", I24 " list of goods banned import", I25 "the catalog banned respecting processing trade " ands" the waste directory which can be used as raw materials respecting automatic import license management " are issued. The imports of the waste and hazardous waste on the list are banned, limited or automatically licensed in accordance with the demands of the lis. The exports of the waste not included on the list are banned by the country.

Third, strictly control the export of hazardous waste .If the environmentally friendly disposal of the hazardous waste is still difficult, the overseas disposal is strictly controlled in accordance with the "provisions of the Basel conventions". The exporters of waste need to apply to the State Environmental Protection Administration. Only after the SEPA gets the consent of the authorities of the importing countries are exports allowed.

Fourth, establish the center of training in managing hazardous waste and technology transfers. In order to promote the implementation of "Basel Convention" in China, on March 6, 1993 the State Environmental Protection Administration set up the center of training in managing hazardous waste and technology transfers in Tsinghua University. On the basis, Our country applied to establish the Asia Pacific Regional hazardous waste management training and technology transfer center, after getting the approval of the general assembly of signatories to the Basel Convention. We provide technical training in managing and disposing hazardous waste, technical advisory services and technology transfers for 42 countries in the Asia Pacific region in order for them to improve the ability to solve the hazardous waste pollution.

Fifth, investigate and deal with illegal cross-border transfers of waste. In order to protect our country's environment and prevent pollution from being transferred, our country cracks down on illegal cross-border transfers of waste .For example, in 1993Nanjing imported chemical waste from South Korean; in 1995 Nanchang imported waste living plastic from Germany, and so on. The 
environmental protection departments ordered that the waste should be transported out in accordance with the "provisions of the Basel conventions", which enhanced our national environmental awareness ,improved the prestige of the Convention in our country and cracked down on illegal cross-borde $r$ transfers of waste

\section{B. The problems respecting legal control of illegal cross-border transfers of hazardous waste}

1) Lax regulation of the environment, weak prevention and slow response

For nearly twenty years of China being a signatory to the convention, we haven't been able to stop developed countries from dumping waste into China effectively .On the contrary, there is a growing trend. Southeast Express reported that in 1997England dumped about one hundred twenty thousand tons of waste into China .However, by 2005England has dumped as much as one thousand and nine hundred thousand tons of waste into China. For the short eight years' time, the amount of waste was one hundred and fifty-eight times as much as before; in 2002 SVTC and BAN jointly announced the results of the investigation into Asian electronic waste imports ,which show in the USA every year about $50-80 \%$ of electronic waste is exported to Asia; the main target is China; 127 besides, “Guijun phenomenon" attracting widespread attention, etc. Toa great degree these incidents show weak regulation of the environment, weak execution, the lack of consciousness of prevention and slow response in China.

2) Ignore the strict environmental standards in the process of economic development

China has adopted the "world factory" model of economic development since the 1980s, which promoted the rapid development of economy, but caused some serious problems. The reason was that not only it consumed a lot of resources, but also some pollution-intensive industries especially high pollution-intensive industries transferred the eliminated technology, equipment, production process, hazardous waste to China. In the production process, these foreign-invested enterprises seriously polluted the environment and greatly destroyed the ecological balance and environmental protection in china. In addition, our country's environmental standards are too low, which was not paid attention to at the initial stage of the economic development, thus causing irreparable damage to our environment.

3) The legal control system is in chaos and the relevant provisions don't fully conform with the Convention.

At present, our country's legal system of cross-border transfers of hazardous waste is not a unified system. The relevant provisions of hazardous waste are mainly dispersed in a variety of laws and regulations, which appears to be fragmentary and cannot give a systematic feeling. The "solid waste law" has made some integration, though. Because in China most of the laws and regulations on scross-border waste are promulgated by different legislatures or the authorized legislatures, some of which are still on certain specific issues of certain periods, they are not logical. So are a lot of waste lists. The reality of the legislation will inevitably lead to the complexity and chaos of hazardous waste control systems .Besides, the "solid waste law" itself has some disadvantages. For example, the specific measures don't match with the basic system; there is a lack of mechanisms for dealing with performance and compliance; the liabilities and compensations are not clear. Most importantly, this law does not fully conform with the Convention. First of all, the definition "solid waste law" still retains the concept of "solid waste", which is not consistent with the provisions of the Convention; secondly, "solid waste law" is not a total ban on the transfer of waste, but the waste is classified and treated, which is not entirely consistent with the Convention.

\section{IMPROVE THE COUNTERMEASURES OF LEGAL CONTROL OF CROSS-BORDER TRANSFERS OF HAZARDOUS WASTE IN CHINA}

\section{A. Further improve the existing management system of hazardous waste}

In "Solid waste law" revised in 2004 the provisions of controlling cross-border transfers of hazardous waste from overseas to China border is still relatively rough. It is suggested that the law and the existing normative documents of relevant departments should be improved in order to formulate a specific administrative regulation --"environmental management regulations of the import and export of hazardous waste ",which systematically regulates the management procedure sand related responsibilities of the import and export of hazardous waste. Meanwhile, our country should timely adjust the import management list of relevant waste, expand the application of the examination and approval system , and cancel the automatic license of imports. Moreover, each conference of signatories to "Basel Convention" adopted many technical documents including the methods of handling and disposal and the technical specifications of treating certain hazardous waste, which was suggested as important reference sto establishing the technology standards of hazardous waste storage, treatment and disposal. In addition, China has also been proposed to carry out the full supervision of hazardous waste. The related business entities of disposing of hazardous waste, waste transport, storage, and the final standard of disposal must comply with the corresponding legal norms. Most importantly, these management measures and laws and regulations are put into practice.

B. The establishment of mechanisms for preventing environmental risks of hazardous waste and the liability and compensation system of hazardous waste

Considering the reality that our country is a "big country of foreign investment" ,our country should establish a strict risk prediction and evaluation system of hazardous waste, in which the whole process of the production, transport, storage, treatment and disposal of 
hazardous waste which may cause damage to human health and the environment should be predicted and prevented. The risk assessment of the pollution and harm of hazardous waste, and unexpected problems is necessary. We should take precautionary measures in advance and emergency response so as to reduce the risk of decision-making and uncertainty in the environmental management. Especially the environmental Assessment of foreign-invested enterprises can not be subject to immediate economic benefits. The costs of environmental aspects must be fully taken into account. Meanwhile, considering the amendment and protocol of the Convention have not taken effect yet. In order to effectively manage the cross-border transfers of hazardous waste to China, China should establish the system of liability, compensation and insurance in order to effectively maintain our legal rights when cross-border transfers of hazardous waste cause damage .In addition, in the framework of the protocol of "Basel Convention", our country should strengthen bilateral agreements with other countries so that we can provide the strong protection compliant with the protocol for the victims. Thus, the related provisions of the Proto colon liability and compensation, should be our reference template of signing bilateral agreements with other countries in the future.

\section{Strengthen the supervision and management of hazardous waste}

First, we should strengthen the supervision and management of the competent authorities ,crackdown on the illegal import of hazardous waste, and always keep the pressure up for regulating the import of hazardous waste and other waste .Customs should increase the supervision of the imported single trial ,risk analysis ,on-site inspection and alls the customs procedure; the environmental protection departments should strengthen the supervision of the acceptance, review, approval for the application for the export of hazardous waste. If necessary, the horizontal linkages between environmental protection departments, industry and commerce, taxation and other departments .They should exchange information, establish a solid liaison and coordination mechanism, and manage together to strictly crack down on the illegal import, processing and production, sale and smuggling of the imported garbage. In addition to strengthening the supervision, the inside jobs and negligent behaviors should be seriously punished. In practice, in many cases illegal waste trade plan is carried out due to each other's collusion and mutual favoritism of private companies, customs, port staff, and even some government department. Therefore, formulating law sand regulations, and cracking down on these people's illegal and criminal acts are also keys to stopping the trade .in the illegal waste.

\section{REFERENCE}

[1] Chen Jun, Zhang Ying; China's current situation and Countermeasures of preventing [J] abroad pollution transfer; Journal of Anqing Teachers College(SOCIAL SCIENCE EDITION) in 2003 .

[2] Wu Jianwei; Chen, the problems should be paid attention [J] the transfer of polluting industries of China's investment in commercial research; in 2003.

[3] Li Xiaoming, Cao Lijun, Han Wenhui; [J]analysis and Countermeasures of pollution transfer; Chongqing environmental science; in 2003.

[4] Zhang Xianglan, Qin Tianbao; the Basel Convention on the control of transboundary movements of hazardous wastes and its latest development: to implement [J] from the framework of law review; 2003 03;

[5] Qin Tianbao; the World Trade Organization [J]law and practice about environmental protection; International Forum in 2000.

[6] Xia Youfu; control of foreign hazardous waste to study countermeasures for China to transfer [J];international trade; in 2008.

[7] Shen Zhanchang; on the control of transboundary movements of hazardous wastes the law system about [J]; Journal of Guangxi Administrative Cadre Institute of politics and law . 2004. 